\title{
FAKTOR-FAKTOR YANG MEMPENGARUHI LOYALITAS KONSUMEN PADA RESTORAN CEPAT SAJI DI KOTA BENGKULU
}

\author{
(FACTORS THAT AFFECTS LOYALTY TYPES OF BUYERS IN FAST FOOD \\ RESTAURANT IN BENGKULU CITY)
}

\author{
Reazi Agusman, Irnad, dan Melli Suryanty* \\ Jurusan Sosial Ekonomi Pertanian Fakultas Pertanian Universitas Bengkulu \\ E-mail: msuryanty@unib.ac.id
}

\begin{abstract}
This study aims to is to find factors affecting loyalty consumers fast food restaurant in Bengkulu City seen from approach extended marketing mix (7p). Variable latent used in this research was extended marketing mix, demografy, customer satisfaction and loyalty consumers. A method of the sample collection with accidental where the sample collection on coincidence and the method of analysis the data used was structural equation modelling (SEM). The method for data analysis was Structural Equation Modeling to examine the causal relationship between observed variables. This study uses two-stage method, where first phased measurement Confirmatory Factor Analysis (CFA) and the second stage measurement was Second Order Confirmatory Factor Analysis (CFA-2). From the Googness Of Fit (GOF) 1 a gauge that indicates match a less well, 5 size gof showing match quite good (marginal fit) and 10 size gof showing match the best good fit. So that it can be concluded that match a whole model is good. The final result of this study shows the variables that make up the extended marketing mix is product, price, place, physical evidence and process where this variable has a significant effect on loyalty both direct relationship and consumer satisfaction variable as Intervening variable. While the demographic variables have no significant effect on loyalty variable directly or indirect relationship with satisfaction as intervening variable.
\end{abstract}

Keywords: Loyalty, Extended Marketing Mix, SEM, CFA and GOF

\section{PENDAHULUAN}

Seiring dengan perkembangan zaman secara disadari dan tidak disadari telah banyak mengalami mempengaruhi kehidupan masyarakat. Menurut Rosana (2011) mengemukakan bahwa Modernisasi adalah suatu proses transformasi dari suatu arah perubahan ke arah yang lebih maju atau meningkat dalam berbagai aspek dalam kehidupan masyarakat. Dinamika yang berkembang dimasyarakat terjadi dengan cepat. Pekerjaan yang semakin padat dan waktu istrahat yang sedikit membuat banyak masyarakat saat ini cenderung untuk memilih makanan cepat saji (fast food), dibeberapa kota besar restoran cepat saji tidak hanya dilakukan untuk memenuhi kebutuhan konsumsinya tetapi juga telah menjadi gaya hidup (life style) tersendiri. Meningkatnya masyarakat pada makanan cepat saji membuat usaha dibidang restoran cepat sajji kian meningkat dan tidak mengherankan model usaha waralaba (franchise) menjamur diseluruh indonesia.

Di Kota Bengkulu juga sudah banyak didirikan restoran cepat saji baik yang sifatnya lokal, nasional bahkan internasional. Keberadaan restoran tersebut menambah ragam variasi kuliner yang ditawarkan kepada konsumen. Kepuasan konsumen merupakan hal yang penting dan harus dijaga oleh setiap restoran siap saji guna menarik 
lebih banyak konsumen dan mempertahankan loyalitas konsumen. Untuk itu perusahaan harus lebih inovatif dan kreatif.

Bauran pemasaran (marketing mix) menurut Zeithaml dan Bitner (2001) yang dikutip dalam Hurriyati (2010) menjadi dasar dalam pemasaran yang teridiri dari 4P yaitu product (produk), price (harga), place (tempat/lokasi), promotion (promosi). Akhir-akhir ini dalam perkembangannya ditambahkan " $3 \mathrm{P}$ " pada bauran pemasaran yaitu people (orang), processs (proses), physical evidence (bukti fisik). Bauran pemasaran ini dikenal sebagai extended marketing mix (Sumarwan et al, 2013). Selain itu tingkat kepuasan konsumen juga dipengaruhi oleh konsumen itu sendiri dimana sebagai pelaku pengambilan keputusan. Aspek demografi konsumen juga mempengaruhi dalam proses pengambilan keputusan dan kepuasan konsumen itu sendiri. Menurut Loudon \& Bitta (1993) dalam Saifulloh (2014) bahwa aspek demografi konsumen seperti usia, jenis kelamin, pendidikan dan pekerjaan juga dapat mempengaruhi kepuasan konsumen. Maka dalam penelitian ini akan menentukan faktor-faktor yang mempengaruhi loyalitas konsumen di restoran siap saji di Kota Bengkulu dengan pendekatan Extended Marketing Mix.

\section{METODOLOGI PENELITIAN}

\section{Penentuan Lokasi dan Sampel}

Penentuan lokasi penelitian dlaukan secara sengaja (purposive) yaitu pada salah satu restoran siap saji di kota Bengkulu, yakni Restoran XYZ. Pertimbangan pemilihan lokasi penelitian adalah restoran ini memiliki beberapa cabang usaha yang tersebar di dalam Kota Bengkulu dan termasuk salah satu restoran yang sudah lama beroperasi di Kota Bengkulu. Teknik pengambilan sampel dalam penelitian ini secara accidental dimana pengambilan sampel berdasaran kebetulan, yaitu siapa saja yang secara kebetulan bertemu dengan peneliti dapat digunakan sebagai sampel, bila dipandang orang yang kebetulan ditemui itu cocok sebagai sumber data (Sugiyono, 1999).

Karena pada lokasi peneliti belum mengetahui jumlah populasi, peneliti menggunakan asumsi yang dikemukakan oleh Nasution (2015), jumah sampel yang akan digunakan adalah jumlah variabel manifes dari seiap variabel laten yang digunakan dalam penelitian dikalikan dengan angka 5-10 dengan jumlah sampel untuk pendugaan maximum likehood pada SEM yaitu sebesar 100-200 responden dan minimum sebesar 50 sampel. Dalam penelitian ini variabel manifes berjumlah 17 variabel, angka pengali adalah 6 dipilih secara purposive oleh peneliti atau disengaja dengan pertimbangan kemampuan peneliti dalam pengerjaan maupun biaya penelitian. Maka yang menjadi responden dalam penelitian ini yaitu 17 (variabel manifes) x 6 (angka pengali) = 102 respondenDimana jumlah sampel yang digunakan adalah sebanyak 102 sampel.

\section{Metode Analisis Data}

Metode analisi data yang digunakan dalam penelitian ini menggunkan metode analisis deskriptif dan metode Structural Equation Modelling (SEM). Berikut penjelasan mengenai metode yang digunakan dalam menganalisis data penelitian.

\section{Analisis Deskriptif}

Untuk mengetahui karakteristik konsumen (responden) pada restoran XYZ di Kota Bengkulu dengan menggunakan analisis deskriptif. Analisis deskriptif yaitu metode yang digunakan untuk mewawancarai para konsumen yang telah membeli atau sedang 
membeli produk. Analisis deskriptif digunakan untuk menggambarkan keadaan dari karakterisitik umum responden berdasarkan fakta yang terjadi, dengan melihat kuesioner yang disebarkan kepada responden atau pembahasan yang diproleh selama penelitian terhadap konsumen (Patimah, 2016).

\section{Analisis Structural Equation Modeling (SEM)}

Hipotesis yang diuji dalam penelitian ini, antara lain:

H1 Extended Marketing Mix akan berpengaruh signifikan terhadap Kepusan Konsumen

H2 Extended Marketing Mix akan berpengaruh signifikan terhadap Loyalitas Konsumen

H3 Demografy akan berpengaruh signifikan terhadap Kepuasan Konsumen

H4 Demografy akan berpengaruh signifikan terhadap Loyalitas Konsumen

H5 Kepuasan Konsumen akan berpengaruh signifikan terhadap Loyalitas Konsumen

Analisis data dilakukan dengan menggunakan structural equation modeling (SEM) denga bantuan piranti lunak LISREL8.80. Menurut (Sarjono,2015) asumsi tersebut mencakup: 1. Spesifikasi model terkait pembentukan model yang merupakan pembentukan antara variabel laten yang satu dengan variabel laten yang lainnya dan juga terkait hubungan antar variabel laten dengan variabel menives sesuai dengan teori yang ada, 2. Identifikasi model, 3. Estimamsi model untuk menentukan nilai estimasi setiap parameter model yang membentuk matrik $\Sigma(\theta)$, sehingga nilai parameter tersebut sedekat mungkin dengan nilai yang ada didalam matriks $S$ (matriks kovarian dari variabel yang teramati/sampel) metode estimasi yang digunakan ialah Maximum Likelihood Estimation (MLE), 4. Uji kecocokan model yang terdiri dari uji kecocokan keseluruhan model (overall model fit), kecocokan model pengukuran (measurement model fit) dan kecocokan model structural (structural model fit). Penentuan faktor atau variabel yang signifikan dilakukan dengan kriteria pengmbilan keputusan yang didasarkan pada nilai Critical Ratio (CR) yang dibandingkan dengan nilai CR tabel yang setara dengan pada nilai t-tabel pada tingkat probabilitas $a=0.05$, yaitu sebesar 1.98. Sedangkan tingkat pengaruh relative dari suatu faktor atau variabel dilihat dari nilai loading factor, semakin tinggi nilai loading factor maka semakin penting pengaruhnya.

\section{HASIL DAN PEMBAHASAN}

\section{KARAKTERISTIK RESPONDEN}

Dalam penelitian ini, responden merupakan konsumen yang telah mengkonsumsi minimal lebih dari satu kali yang memberikan dari sudut pandang Extended Marketing Mix, persepsi terhadap kualitas dan pelayanan restoran XYZ di Kota Bengkulu. Karakterisitik responden yang diamati dalam penelitian ini meliputi: Jenis Kelamin, Umur, Status, Pendidikan Terakhir, Pekerjaan, Pendapatan dan Akses Media.

\section{Konsumen Menurut Jenis Kelamin}

Karakterisitik konsumen berdasarkan jenis kelamin dapat dilihat pada tabel 1.

Tabel 1. Karakterisitik konsumen berdasarkan jenis kelamin

\begin{tabular}{clcc}
\hline No & Jenis Kelamin & $\begin{array}{c}\text { Jumlah } \\
\text { Konsumen }\end{array}$ & Persentase \\
\hline 1 & Perempuan & 72 & 70,59 \\
2 & Laki-laki & 30 & 29,41 \\
\hline
\end{tabular}




Jumlah 102
Sumber : data primer diolah, 2017
Pada tabel 1 dapat dilihat konsumen yang mengkonsumsi pada makanan restoran
cepat saji XYZ di Kota Bengkulu berdasarkan jenis kelamin yaitu perempuan sebesar
$70,59 \%$ dan laki-laki $29,41 \%$. Restoran cepat saji XYZ merupakan restoran yang
menyediakan jenis menu yang menarik bagi konsumen terutama bagi anak remaja pada
saat ini yang senang berkumpul dengan menikmati hidangan makanan yang disediakan.
Sehingga apabila dilihat dari persentase jenis kelamin wanita paling dominan karena
remaja wanita lebih sering dan senang berkumpul bersama teman-temannya (Wulansari,
2015).

\section{Konsumen Menurut Umur}

Umur merupakan salah satu faktor yang mempengaruhi seseorang dalam melakukan aktifitas mereka serta minat konsumsi juga ditunjukkan dari umur. Sehingga umur konsumen menyebabkan perbedaan selera konsumen dalam membeli dan mengonsumsi suatu produk. Menurut WHO dalam klasifikasi umur antara lain : masa balita 0-5 tahun, masa anak-anak 6-11 tahun, masa remaja 12-17 tahun, masa dewasa 1840 tahun dan masa tua 45-65 tahun. Pada penelitian ini dapat dilihat karakterisitik responden berdasarkan umur pada tabel 2 .

Tabel 2. Karakteristik Konsumen Berdasarkan Umum menurut WHO

\begin{tabular}{clc}
\hline No & Kelompok Umur & Jumlah Konsumen \\
\hline 1 & $0-5$ (Balita) & 0 \\
2 & $6-11$ (Anak-anak) & 0 \\
3 & $12-17$ (Remaja) & 23 \\
4 & $18-40$ (Dewasa) & 2 \\
5 & $45-65$ (Masa Tua) & 102 \\
\hline
\end{tabular}

Sumber : data primer diolah, 2017

Usia mempengaruhi seseorang dalam mengambil keputusan. Anak-anak mengambil keputusan dengan cepat, cenderung tidak terlalu banyak pertimbangan. Ketika membuat keputusan remaja sudah mulai mempertimbangkan desain, mode, dan lain-lain, mereka cenderung emosional. Keputusan pembelian yang dilakukan oleh orang tua cenderung rasional, banyak yang dipertimbangkan seperti harga, manfaat dan lainlain (Sangadji dan Sopiah, 2013).

Pada tabel 2 menunjukkan konsumen restoran XYZ di Kota Bengkulu dominan pada umur 18-40 tahun yang dikategorikan dewasa. Hal ini juga sejalan dengan banyaknya penduduk yang berada pada rentang usia tersebut. Pada usia ini juga sejalan dengan informasi yang didapatkan dari lapangan bahwa pengunjung banyak dari kalangan muda yang suka berkumpul bersama teman-teman terdiri dari kalangan SMP, SMA dan Mahasiswa.

\section{Konsumen Menurut Status Pernikahan}

Karakteristik konsumen berdasarkan Status pernikahan dapat dilihat pada tabel 3 berikut:

Tabel 3. Karakterisitik konsumen berdasarkan Status Pernikahan

\begin{tabular}{llll}
\hline No & Status Pernikahan & Jumlah Konsumen & Persentase (\%) \\
\hline
\end{tabular}




\begin{tabular}{llll}
\hline 1 & Belum Menikah & 84 & 82,35 \\
2 & Menikah & 18 & 17,65 \\
\hline & Jumlah & 102 & 100 \\
\hline
\end{tabular}

Sumber : data primer diolah, 2017

Dari keseluruhan responden data penelitian ini sebesar 82,35\% merupakan konsumen yang belum menikah dan $17,65 \%$ responden adalah konsumen yang telah menikah. Hal ini dikarenakan beberapa faktor seperti pertimbangan pertimbangan dalam sebuah keputusan pembelian. Hal ini juga sejalan dengan umur responden yang masih dikategorikan remaja dan dewasa dimana rata-rata sebagian besar berada pada umur 1523 tahun dimana merupakan masih berpendidikan SMP, SMA dan Mahasiswa.

Menurut informasi dari lapangan mereka yang telah menikah datang ke restoran XYZ tidak hanya atas keinginan sendiri, terkadang keinginan dari istri ataupun anak. Menurut Simanora (2004) dalam Adiyoga (2012), biasanya orang yang telah berkeluarga dan memiliki anak, maka mereka akan memberikan asupan makanan yang bergizi untuk anak mereka. Orang tua akan memberikan yang terbaik untuk anak mereka dalam perkembangannya, baik dalam pertumbuhan badannya dan juga perkembangan kecerdasan otak.

\section{Konsumen Menurut Pendidikan Terakhir}

Tingkat pendidikan terakhir mempengaruhi pola pikir dari seseorang sehingga berdampak pada keputusan konsumen. Lamanya tingkat pendidikan yang ditempuh akan mempengaruhi proses keputusan akhir konsumen dan dalam penelitian ini sangat beragam dari lulusan SD, SMP, SMA serta Perguruan Tinggi (PT). Karakteristik konsumen restoran XYZ di Kota Bengkulu dapat dilihat pada tabel 4.

Tabel 4. Karakterisitik Responden Menurut Pendidikan Terakhir

\begin{tabular}{clcc}
\hline No & Pendidikan Terakhir & Jumlah Konsumen & Persentase (\%) \\
\hline 1 & SD & 13 & 12,75 \\
2 & SMP & 12 & 11,76 \\
3 & SMA & 48 & 47,06 \\
4 & PT (Strata dan Diploma) & 29 & 28,43 \\
\hline & Jumlah & $\mathbf{1 0 2}$ & $\mathbf{1 0 0}$ \\
\hline
\end{tabular}

Sumber : data primer diolah, 2017

Berdasarkan tabel 4 konsumen terbanyak berdasarkan pendidikan terakhir yaitu pendidikan terakhir SMA sebesar $47,06 \%$ diikuti pendidikan terakhir Perguruan Tinggi (Strata dan Diploma) sebesar 28,43\%, pendidikan terakhir SD dan SMP berada pendidikan terakhir paling kecil dengan jumlah persentase dari keseluruhan sebesar $12,75 \%$ dan $11,76 \%$. Hal ini dapat dilihat bahwa mengonsumsi makanan di restoran cepat saji telah menjadi life style tersendiri bagi konsumen.

\section{Konsumen Menurut Pekerjaan}

Salah satu karakteristik responden yang dapat dilihat adalah menurut pekerjaan. Pekerjaan konsumen berpengaruh terhadap proses pengambilan keputusan karena berhubungan dengan kemampuan konsumen naik dari pendapatan maupun waktu senggang konsumen. Karakteristik konsumen menurut pekerjaan dapat dilihat pada tabel 5 berikut:

Tabel 5. Karakterisitik Responden Menurut Pekerjaan 


\begin{tabular}{llcc}
\hline No & \multicolumn{1}{c}{ Pekerjaan } & Jumlah Konsumen & Persentase (\%) \\
\hline 1 & Pelajar & 25 & 24,51 \\
2 & Mahasiswa/Mahasiswi & 39 & 38,24 \\
3 & Pegawai Negeri & 13 & 12,75 \\
4 & Pegawai Swasta & 11 & 10,78 \\
5 & Wiraswasta & 9 & 8,82 \\
6 & Lainnya & 5 & 4,90 \\
\hline & Jumlah & $\mathbf{1 0 2}$ & $\mathbf{1 0 0}$ \\
\hline
\end{tabular}

Sumber : data primer diolah, 2017

Berdasarkan tabel 5 dapat dilihat bahwa yang menjadi konsumen terbanyak berprofesi sebagai mahasiswa/mahasiswi dengan persentase 38,24\% dari keseluruhan, diikuti pelajar sebanyak $24,51 \%$ terdiri dari pelajar SMP dan pelajar SMA. Sedangkan untuk pegawai negeri yang terdiri dari berbagai profesi seperti dosen, staff PNS, Polri, Staff BNN, Staff BUMN, Polhut, dll. Untuk pegawai swasta sebanyak 10,78\% serta wiraswasta sebanyak $8,82 \%$. Paling sedikit dengan persentase sebesar 4,9 persen terdiri dari profesi IRT, honorer, dan pengangguran seperti seorang yang baru lulus Perguruan Tinggi.

Hasil penyajian karakteristik responden menurut pekerjaan ini searah dengan banyaknya pengunjung dari kalangan muda dan didominasi oleh kalangan mahasiswa/mahsiswi. Kalangan mahasiswa dan kalangan mahasiswi merupakan kalangan yang mempunyai waktu lebih dan kesempatan besar berkumpul dengan temanteman. Banyak dari kalangan mahasiswa yang memilih untuk berkumpul, membuat tugas bersama serta menjadi tempat nongkrong bagi kalangan ini. Hal ini juga diikuti dengan kalangan pelajar mulai dari pelajar SMP dan SMA.

\section{Konsumen Menurut Pendapatan}

Karakteristik konsumen menurut pendapatan sangat mempengaruhi pada pola konsumsi sesorang. Karakteristik konsumen menurut pendapatan pada restoran cepat saji XYZ di Kota Bengkulu dapat dilihat pada tabel 6.

Tabel 6. Karakterisitik Responden Menurut Pendapatan

\begin{tabular}{llcc}
\hline No & Pendapatan (Rupiah) & Jumlah Konsumen & Persentase (\%) \\
\hline 1 & $0-1.500 .000$ & 70 & 68,63 \\
2 & $1.600 .000-3.100 .000$ & 17 & 16,67 \\
3 & $3.200 .000-4.700 .000$ & 10 & 9,80 \\
4 & $4.800 .000-6.300 .000$ & 3 & 2,94 \\
5 & $6.400 .000-7.900 .000$ & 2 & 1,96 \\
\hline & Jumlah & $\mathbf{1 0 2}$ & $\mathbf{1 0 0}$ \\
\hline
\end{tabular}

Sumber : data primer diolah, 2017

Pendapatan seseorang akan berpengaruh pada daya beli dan pola konsumsi. Hal ini dikarenakan pendapatan menjadi indikator penting untuk mengetahui daya beli konsumen yang bisa diketahui dari besarnya jumlah produk yang bisa dibeli oleh konsumen (Sumarwan, 2003). Sehingga pendapatan konsumen sangat mempengaruhi tingkat pembelian pada suatu produk. Hal ini akan mempengaruhi kepuasan konsumen terutama pada tingkat harga pada suatu produk.

Pada tabel 6 dapat dilihat bahwa pendapatan konsumen dominan dari Rp.0Rp.1500.000 hal ini menunjukkan bahwa banyaknya kalangan pelajar dan mahasiswa 
yang memiliki pendapatan pada rentang tersebut. Hal ini juga menunjukkan produk restoran XYZ terjangkau pada semua kalangan baik dari pelajar, mahasiswa maupun pada profesi lainnya.

\section{Konsumen Menurut Akses Media}

Akes media merupakan salah satu hal penting dalam sebuah pemasaran terutama dari bauran promosi. Akses media menjadi peranan penting dalam mendapatkan informasi tertentu seperti informasi nilai gizi, harga, dan kualitas dari suatu produk. Berikut karakteristik konsumen menurut Akkses Media terlihat pada tabel 7.

Tabel 7. Karakterisitik Responden Menurut Akses Media

\begin{tabular}{cccccccllll}
\hline \multirow{2}{*}{ No } & Media & \multicolumn{3}{c}{ Jumlah Konsumen } & \multirow{2}{*}{ Total } & \multicolumn{4}{c}{ Persentase (\%) } & \multirow{2}{*}{ Total } \\
\cline { 3 - 4 } & Cetak & Ya & Kadang & Tidak & & Ya & Kadang & Tidak & \\
\hline 1 & Internet & 54 & 13 & 5 & 102 & 2.94 & 12.75 & 34.31 & 100 \\
2 & Televisi & $\mathbf{9 4}$ & 1 & 7 & 102 & $\mathbf{2 . 1 6}$ & 0.98 & 6.86 & 100 \\
3 & Cetak & 42 & $\mathbf{2 2}$ & $\mathbf{3 8}$ & 102 & 1.18 & $\mathbf{2 1 . 5 7}$ & $\mathbf{3 7 . 2 5}$ & 100 \\
\hline
\end{tabular}

Sumber : data primer diolah, 2017

Dari tabel 7 diatas tidak semua konsumen mempunyai akses ke berbagai media. Pada konsumen restoran cepat saji XYZ di Kota Bengkulu dikelompokkan menjadi tiga media yaitu media internet, tevisi atau audio-visual dan media cetak. Pada media internet konsumen yang mempunyai akses ke media tersebut sebanyak 52,94\%, kadang-kadang mempunyai akses dan tidak sebanyak $34,31 \%$ hal ini dikarenakan konsumen banyak bergantung pada wifi seperti wifi pada lembaga instansi dan lain-lain. Konsumen yang tidak mempunyai sama sekali akses ke media internet yaitu sebanyak $34,31 \%$.

Untuk media televisi konsumen yang mempunyai akses penuh sebanyak 92,16\% atau hampir keseluruhan mempunyai akses ke media audio-visual ini. Konsumen sebanyak 0,98\% kadang-kadang mempunyai akses hal ini dimungkinkan karena tidak harus mempunyai televisi sendiri dirumah. Dan yang tidak mempunyai akses ke media televisi sebanyak 6,86\% hal ini juga berdasarkan banyaknya konsumen yang berprofesi sebagai mahasiswa dan tidak semuanya berada tinggal dengan orang tua sendiri.

Pada media cetak konsumen cenderung sedikit akses hal ini dibuktikan dimana konsumen yang mempunyai akses penuh sebanyak 41,18\%, sedangkan konsumen yang kadang-kadang mempunyai akses ke media cetak sebanyak $21,57 \%$ hal ini dikarenakan tidak setiap hari konsumen membeli media cetak seperti koran ataupun majalah. Konsumen yang tidak mempunyai akses ke media cetak sebanyak 37,25\% hal ini dikarenakan banyaknya dari kalangan muda seperti pelajar dan mahasiswa yang kurang berminat untuk membaca media cetak dan lebih memilih media lain sperti televisi dan internet.

\section{ANALISIS TANGGAPAN TERHADAP VARIABEL LATEN EXTENDED MARKETING $\operatorname{MIX}(E X)$}

\section{Tanggapan Konsumen Terhadap Product (X1)}

Produk merupakan salah satu bauran pemasaran yang paling penting, seseorang kosumen tentu akan melihat produk apa yang ditawarkan oleh suatu produsen baru stelahnya akan memutuskan untuk membeli atau tidak. Dalam penelitian ini variabel 
manifest produk terbagi kedalam 7 indikator item pertanyaan. Tujuh indikator item ini lah yang membentuk keseluruhan variabel produk, indikator item pertanyaan tersebut adalah variasi dan inovasi, rasa, kehiegenisan produk, porsi yang pas, kemasan yang praktis dan menarik, kualitas bahan. Untuk lebih jelasnya bisa dilihat persentase tanggapan konsumen terhadap item-item pertanyaan dari indikator variabel produk makanan cepat saji di XYZ Kota Bengkulu pada tabel 8 berikut ini.

Tabel 8. Persentase Tanggapan Konsumen Terhadap Bauran Product

\begin{tabular}{|c|c|c|c|c|c|c|}
\hline \multirow[b]{2}{*}{ No } & \multirow[b]{2}{*}{ Indikator Varibel Product } & \multicolumn{5}{|c|}{ Banyak Konsumen } \\
\hline & & $\begin{array}{l}\text { Sangat } \\
\text { Tidak } \\
\text { Setuju }\end{array}$ & $\begin{array}{l}\text { Tidak } \\
\text { Setuju }\end{array}$ & $\begin{array}{l}\text { Kurang } \\
\text { Setuju }\end{array}$ & Setuju & $\begin{array}{l}\text { Sangat } \\
\text { Setuju }\end{array}$ \\
\hline 1 & $\begin{array}{l}\text { Menu XYZ memiliki variasi dan } \\
\text { inovasi yang banyak. }\end{array}$ & $1 \%$ & $0 \%$ & $5 \%$ & $78 \%$ & $16 \%$ \\
\hline 2 & $\begin{array}{l}\text { Menu XYZ memiliki rasa yang enak } \\
\text { dan sesuai dengan selera anda. }\end{array}$ & $0 \%$ & $0 \%$ & $6 \%$ & $75 \%$ & $20 \%$ \\
\hline 3 & $\begin{array}{l}\text { Produk } X Y Z \text { memiliki kehigienisan } \\
\text { yang terjaga dengan baik. }\end{array}$ & $1 \%$ & $1 \%$ & $11 \%$ & $75 \%$ & $12 \%$ \\
\hline 4 & $\begin{array}{l}\text { Porsi pada menu XYZ sudah pas } \\
\text { dengan anda. }\end{array}$ & $2 \%$ & $11 \%$ & $23 \%$ & $57 \%$ & $8 \%$ \\
\hline 5 & $\begin{array}{l}\text { Tampilan produk XYZ praktis dan } \\
\text { menarik. }\end{array}$ & $1 \%$ & $1 \%$ & $11 \%$ & $79 \%$ & $8 \%$ \\
\hline 6 & $\begin{array}{l}\text { XYZ menggunakan bahan-bahan yang } \\
\text { berkualitas }\end{array}$ & $0 \%$ & $1 \%$ & $17 \%$ & $75 \%$ & $8 \%$ \\
\hline 7 & $\begin{array}{l}\text { Bahan-bahan yang digunakan oleh } \\
\text { XYZ terjamin/terstandar dengan jelas. }\end{array}$ & $0 \%$ & $1 \%$ & $16 \%$ & $72 \%$ & $12 \%$ \\
\hline
\end{tabular}

Sumber : data primer diolah, 2017

Dari ketujuh indikator tersebut rata-rata 70\% konsumen menjawab setuju dan ratarata sangat setuju sebanyak $10 \%$ sehingga bisa dikatakan bahwa XYZ memilki menu bervariasi dan inovasi yang banyak, memilki rasa yang sesuai selera konsumen, memiliki kehigienissan yang terjaga dengan baik, tampilan dari produk XYZ menarik dan praktis, bahan-bahan yanng digunakan dirasa berkualitas dan terjaga dengan baik.

\section{Tanggapan Konsumen Terhadap Price (X2)}

Tabel 9. Persentase Tanggapan Konsumen Terhadap Bauran Price

\begin{tabular}{|c|c|c|c|c|c|c|}
\hline \multirow[b]{2}{*}{ No } & \multirow[b]{2}{*}{ Indikator Varibel Price } & \multicolumn{5}{|c|}{ Banyak Konsumen } \\
\hline & & $\begin{array}{c}\text { Sangat } \\
\text { Tidak } \\
\text { Setuju }\end{array}$ & $\begin{array}{l}\text { Tidak } \\
\text { Setuju }\end{array}$ & $\begin{array}{c}\text { Kurang } \\
\text { Setuju }\end{array}$ & Setuju & $\begin{array}{l}\text { Sangat } \\
\text { Setuju }\end{array}$ \\
\hline 1 & $\begin{array}{l}\text { Penetapan harga yang dilakukan } \mathrm{XYZ} \\
\text { sudah sesuai standart. }\end{array}$ & $1 \%$ & $3 \%$ & $19 \%$ & $68 \%$ & $10 \%$ \\
\hline 2 & $\begin{array}{l}\text { Adanya diskon harga yang dilakukan } \\
\text { oleh XYZ pada pembelian tertentu. }\end{array}$ & $2 \%$ & $4 \%$ & $20 \%$ & $54 \%$ & $21 \%$ \\
\hline 3 & $\begin{array}{l}\text { Harga yang diterapkan XYZ bersaing } \\
\text { dengan restoran lainya. }\end{array}$ & $0 \%$ & $3 \%$ & $30 \%$ & $64 \%$ & $3 \%$ \\
\hline 4 & Harga yang diterapkan XYZ sudah & $1 \%$ & $1 \%$ & $22 \%$ & $69 \%$ & $8 \%$ \\
\hline
\end{tabular}


sesuai produk.

Sumber : data primer diolah, 2017

Dari hasil tabel diatas dapat dilihat bahwa variabel manifest harga ditentukan dari 9 indikator item pertanyaan. Hasil yang didapat lebih dari 50\% konsumen menjawab setuju dan sangat setuju sehingga bisa dikatakan bahwa harga yang ditawarkan oleh pihak XYZ telah memenuhi standar, terdapat diskon harga pada pembelian tertentum harga bersaing dengan perusahaan lain, dan harga sudah sesuai dengan kualitas roduk yang disarankan konsumen.

\section{Tanggapan Konsumen Terhadap Place (X3)}

Bauran tempat menjadi penting dalam mencapai target pasar yang dituju, lokasi yang strategis tentuk akan lebih menguntungkan bagi produsen serta konsumen akan lebih mudah mencapai tempat distribusi tersebut. Dapat dilihat pada tabel dibawah ini: Tabel 10. Persentase Tanggapan Konsumen Terhadap Bauran Place

\begin{tabular}{ccccccc}
\hline & & \multicolumn{4}{c}{ Banyak Konsumen } \\
\cline { 3 - 6 } No & \multicolumn{1}{c}{ Indikator Varibel Place } & $\begin{array}{c}\text { Sangat } \\
\text { Tidak } \\
\text { Setuju }\end{array}$ & $\begin{array}{c}\text { Tidak } \\
\text { Setuju }\end{array}$ & $\begin{array}{c}\text { Kurang } \\
\text { Setuju }\end{array}$ & Setuju & $\begin{array}{c}\text { Sangat } \\
\text { Setuju }\end{array}$ \\
\hline 1 & $\begin{array}{l}\text { Lokasi/tempat restoran merupakan } \\
\text { lokasi yang mudah dijangkau dan } \\
\text { strategis. }\end{array}$ & $2 \%$ & $6 \%$ & $18 \%$ & $56 \%$ & $19 \%$ \\
2 & $\begin{array}{l}\text { XYZ di Kota Bengkulu selalu memiliki } \\
\text { ketersediaan produk yang diinginkan } \\
\text { konsumen. }\end{array}$ & $1 \%$ & $2 \%$ & $34 \%$ & $61 \%$ & $2 \%$ \\
3 & $\begin{array}{l}\text { Sarana transportasi menuju lokasi XYZ } \\
\text { mudah didapatkan. }\end{array}$ & $1 \%$ & $4 \%$ & $17 \%$ & $68 \%$ & $11 \%$ \\
\hline
\end{tabular}

Sumber : data primer diolah, 2017

Dari hasil tabel diatas dapat dilihat bahwa variabel manifest tempat ditentukan dari 3 indikator item pertanyaan. Hasil yang didapat lebih dari 50\% konsumen menjawab setuju dan sangat setuju sehingga bisa dikatakan bahwa lokasi XYZ merupakan lokasi yang mudah dan strategis, memiliki ketersediaan produk yang diinginkan konsumen dan saran untuk menuju lokasi mudah didapat.

\section{Tanggapan Konsumen Terhadap Promotion (X4)} berikut:

Untuk hasil tanggapan konsumen dari bauran promotion dapat dilihat pada tabel

Tabel 11. Persentase Tanggapan Konsumen Terhadap Bauran Promotion

\begin{tabular}{|c|c|c|c|c|c|c|}
\hline \multirow[b]{2}{*}{$\begin{array}{c}\mathrm{N} \\
\mathrm{o}\end{array}$} & \multirow[b]{2}{*}{ Indikator Varibel Promotion } & \multicolumn{5}{|c|}{ Banyak Konsumen } \\
\hline & & $\begin{array}{l}\text { Sangat } \\
\text { Tidak } \\
\text { Setuju }\end{array}$ & $\begin{array}{l}\text { Tidak } \\
\text { Setuju }\end{array}$ & $\begin{array}{l}\text { Kurang } \\
\text { Setuju }\end{array}$ & Setuju & $\begin{array}{l}\text { Sangat } \\
\text { Setuju }\end{array}$ \\
\hline 1 & Periklanan melalui media visual. & $0 \%$ & $2 \%$ & $7 \%$ & $77 \%$ & $14 \%$ \\
\hline 2 & $\begin{array}{l}\text { Promosi yang dilakukan XYZ pada media } \\
\text { cetak. }\end{array}$ & $0 \%$ & $2 \%$ & $31 \%$ & $58 \%$ & $9 \%$ \\
\hline 3 & $\begin{array}{l}\text { Personal selling dalam memberikan } \\
\text { informasi detail yang dilakukan pihak } \\
\text { XYZ. }\end{array}$ & $0 \%$ & $2 \%$ & $46 \%$ & $49 \%$ & $3 \%$ \\
\hline 4 & $\begin{array}{l}\text { XYZ melakukan penjualan dengan } \\
\text { memberikan hadih (dalam bentuk apapun } \\
\text { seperti voucher, CD dll). }\end{array}$ & $2 \%$ & $2 \%$ & $13 \%$ & $64 \%$ & $20 \%$ \\
\hline
\end{tabular}


DOI: https://doi.org/10.22437/jiseb.v21i1.5101

Sumber : data primer diolah, 2017

Dari hasil tabel diatas dapat dilihat bahwa variabel promosi sudah cukup baik dimana dari jumalh konsumen yang telah menjawab setuju dan sangat setuju sudah lebih dari 50\%. Maka disimpulkan promosi melalui media visual, media cetak, personal selling dan promo hadiah sudah cukup baik walaupun pada personla selling $56 \%$ konsumen kurang setuju.

\section{Tanggapan Konsumen Terhadap People (X5)}

Untuk hasil tanggapan konsumen dari bauran people dapat dilihat pada tabel berikut: Tabel 12. Persentase Tanggapan Konsumen Terhadap Bauran People

\begin{tabular}{ccccccc}
\hline $\mathrm{N}$ & \multicolumn{1}{c}{ Indikator Varibel People } & $\begin{array}{c}\text { Sangat } \\
\text { Tidak } \\
\text { S }\end{array}$ & $\begin{array}{c}\text { Sidaju } \\
\text { Setuju }\end{array}$ & $\begin{array}{c}\text { Kurang } \\
\text { Setuju }\end{array}$ & Setuju & $\begin{array}{c}\text { Sangat } \\
\text { Setuju }\end{array}$ \\
\hline 1 & $\begin{array}{l}\text { Karyawan XYZ melayani konsumen } \\
\text { dengan ramah dan sopan. }\end{array}$ & $0 \%$ & $2 \%$ & $16 \%$ & $68 \%$ & $15 \%$ \\
2 & $\begin{array}{l}\text { Karyawan memiliki hubungan baik } \\
\text { dengan konsumen. }\end{array}$ & $0 \%$ & $2 \%$ & $20 \%$ & $68 \%$ & $11 \%$ \\
3 & $\begin{array}{l}\text { Kecakapan atau kemampuan karyawan } \\
\text { menjalankan tugasnya dengan sangat } \\
\text { baik. }\end{array}$ & $0 \%$ & $1 \%$ & $15 \%$ & $76 \%$ & $8 \%$ \\
$\begin{array}{l}\text { Karyawan XYZ berpenampilan baik dan } \\
\text { menarik. }\end{array}$ & $0 \%$ & $1 \%$ & $6 \%$ & $81 \%$ & $12 \%$ \\
\hline
\end{tabular}

Sumber : data primer diolah, 2017

Dari hasil tabel diatas dapat dilihat bahwa variabel people sudah cukup baik dimana dari jumlah konsumen yang telah menjawab setuju dan sangat setuju sudah lebih dari 70\%. Maka disimpulkan karyawan XYZ telah melayani konsumen denagn ramah dan sopan, berhubungan baik dengan konsumen, berpenampilan baik serta memiliki kemampuan dalam menjalankan tugasnya dengan baik.

\section{Tanggapan Konsumen Terhadap Physical evidence (X6)}

Untuk hasil tanggapan konsumen dari bauran people dapat dilihat pada tabel berikut:

Tabel 13. Persentase Tanggapan Konsumen Terhadap Bauran Physical evidence

\begin{tabular}{ccccccc}
\hline & & \multicolumn{4}{c}{ Banyak Konsumen } \\
\cline { 3 - 6 } No Indikator Varibel Produk & $\begin{array}{c}\text { Sangat } \\
\text { Tidak } \\
\text { Setuju }\end{array}$ & $\begin{array}{c}\text { Tidak } \\
\text { Setuju }\end{array}$ & $\begin{array}{c}\text { Kurang } \\
\text { Setuju }\end{array}$ & Setuju & $\begin{array}{c}\text { Sangat } \\
\text { Setuju }\end{array}$ \\
\hline 1 & $\begin{array}{l}\text { Fasilitas pendukung yang disediakan } \\
\text { oleh XYZ sangat bagus dan lengkap. }\end{array}$ & $0 \%$ & $1 \%$ & $10 \%$ & $76 \%$ & $13 \%$ \\
2 & $\begin{array}{l}\text { Penggunaan furniture bervariasi dan } \\
\text { dapat diatur sesuai permintaan } \\
\text { konsumen. }\end{array}$ & $1 \%$ & $3 \%$ & $13 \%$ & $70 \%$ & $14 \%$ \\
3 & $\begin{array}{l}\text { Desain eksterior sangat bagus dan } \\
\text { tertata dengan baik. }\end{array}$ & $2 \%$ & $5 \%$ & $13 \%$ & $75 \%$ & $6 \%$ \\
4 & $\begin{array}{l}\text { Desain interior sangat bagus dan tertata } \\
\text { dengan baik. }\end{array}$ & $1 \%$ & $2 \%$ & $13 \%$ & $77 \%$ & $7 \%$ \\
\hline XYZ menyediakan tempat bermain & $1 \%$ & $0 \%$ & $4 \%$ & $70 \%$ & $25 \%$
\end{tabular}


anak-anak.

6 Tempat bermain anak-anak yang $0 \% \quad 4 \% \quad 14 \% \quad 68 \% \quad 15 \%$ disediakan aman dan nyaman.

Sumber : data primer diolah, 2017

Dari hasil tabel diatas dapat dilihat bahwa rata-rata konsumen telah menjawab setuju sehingga bisa dismpulkan dari fasilitas, furniture, desain eksterior dan interior, tempat bermain anak sudah baik, lengkap, tertata dengan baik dan nyaman.

\section{Tanggapan Konsumen Terhadap Proces (X7)}

Untuk hasil tanggapan konsumen dari bauran proces dapat dilihat pada tabel berikut:

Tabel 14. Persentase Tanggapan Konsumen Terhadap Bauran Proces

\begin{tabular}{ccccccc}
\hline $\mathrm{N}$ & Indikator Varibel Produk & \multicolumn{4}{c}{ Banyak Konsumen } \\
\cline { 3 - 6 } $\mathrm{o}$ & $\begin{array}{c}\text { Sangat } \\
\text { Tidak } \\
\text { Setuju }\end{array}$ & $\begin{array}{c}\text { Tidak } \\
\text { Setuju }\end{array}$ & $\begin{array}{c}\text { Kurang } \\
\text { Setuju }\end{array}$ & Setuju & $\begin{array}{c}\text { Sangat } \\
\text { Setuju }\end{array}$ \\
\hline 1 & $\begin{array}{l}\text { Pelayanan untuk pemesanan yang } \\
\text { dilakukan XYZ sangat baik. }\end{array}$ & $0 \%$ & $2 \%$ & $12 \%$ & $79 \%$ & $7 \%$ \\
2 & $\begin{array}{l}\text { Saat ada keluhan dari pelanggan pihak } \\
\text { XYZ menanggapi dengan sangat baik. }\end{array}$ & $2 \%$ & $2 \%$ & $19 \%$ & $71 \%$ & $7 \%$ \\
3 & $\begin{array}{l}\text { Waktu dalam menangapi keluhan dari } \\
\text { pelanggan sangat cepat. }\end{array}$ & $2 \%$ & $3 \%$ & $23 \%$ & $68 \%$ & $5 \%$ \\
\hline
\end{tabular}

Sumber : data primer diolah, 2017

Dari hasil tabel diatas dapat dilihat bahwa rata-rata konsumen telah menjawab setuju sehingga bisa disimpulkan bahwa XYZ telah baik telah melakukan pelyanan dengan baik, menanggapi setiap ada keluahan dari konsumen serta tidak menunda-nuda dalam menanggapi dan mengambil tidakan jika ada konsumen yang mengeluh.

\section{ANALISIS TANGGAPAN TERHADAP VARIABEL LATEN DEMOGRAPHIC (DG) Variabel Umur (X8)}

Untuk variabel umur dikategorikan menjadi 5 kategori dimana dilihat nilai terendah dan terkecilnya. Umur terendah konsumen adalah 15 tahun, hal ini dikarenakan pemilihan oleh peneliti dengan asumsi bahwa seseorang yang berada pada umur 15 tahun telah bisa memberikan informasi sesuia dengan yang dikehendaki oleh peneliti. Sedangkan batasan umur tertinggi adalah 60 tahun. Karakteristik variabel demografi menurut umur dapat dilihat pada tabbel 11 berikut ini:

Tabel 15. Karakteristik Variabel Demografy Konsumen Menurut Umur

\begin{tabular}{cccc}
\hline No & Kelompok Umur (tahun) & $\begin{array}{c}\text { Jumlah Konsumen } \\
\text { (Orang) }\end{array}$ & Persentase \\
\hline 1 & $15-23$ & 74 & $72.55 \%$ \\
2 & $24-32$ & 18 & $17.65 \%$ \\
3 & $33-41$ & 6 & $5.88 \%$ \\
4 & $42-50$ & 3 & $2.94 \%$ \\
5 & $51-59$ & 1 & $0.98 \%$ \\
\hline & Jumlah & 102 & $100 \%$ \\
\hline
\end{tabular}

Sumber : data primer diolah, 2017

Dari tabel diatas dapat dilihat bahwa konsumen dominan berada pada rentang umur 15-23 tahun. hal ini dikarenakan konsumen XYZ rata-rata merupakan dari golongan 
Mahasiswa, siswa SMA dan SMP. Diikuti dengan rentang umur lain dimana semakin tinggi rentang umur semakin sedikit jumlah persentase konsumennya.

\section{Variabel Pendapatan (X9)}

Pendapatan akan menentukan daya beli konsumen, dalam penelitian ini dilihat daya beli konsumen itu sendiri. pendapatan terendah konsume adalh 0 yaitu seorang ibu ruah tangga, dan terdapat beberapa kosumen yang tidak memiliki pekerjaan seperti wisudawan fresh graduation sehingga belum memiliki pekerjaan tetapi memiliki pendapatan dari uang saku. Pendapatan dibagi menjadi 5 kategori dapat dilihat pada tabel berikut:

Tabel 16. Karakteristik Variabel Pendapatan Konsumen Menurut Pendapatan

\begin{tabular}{|c|c|c|c|}
\hline No & Pendapatan (Rupiah) & Jumlah Konsumen & Persentase (\%) \\
\hline 1 & $0-1.500 .000$ & 70 & 68,63 \\
\hline 2 & $1.600 .000-3.100 .000$ & 17 & 16,67 \\
\hline 3 & $3.200 .000-4.700 .000$ & 10 & 9,80 \\
\hline 4 & $4.800 .000-6.300 .000$ & 3 & 2,94 \\
\hline 5 & 6.400.000-7.900.000 & 2 & 1,96 \\
\hline \multicolumn{2}{|c|}{ Jumlah } & 102 & 100 \\
\hline
\end{tabular}

Sumber : data primer diolah, 2017

Hal ini dapat dikatakan bahwa dengan pendapatan yang semakin tinggi tidak menjamin akan semaakin sering mengunjungi XYZ. Bahkan semakin sedikit konsumen dengan pendapatan yang semakin tinggi. Pendapatan yang berbeda tentu akan menimbulkan persepsi konsumen yang berbeda sehingga tingkat kepuasan juga dimungkinkan dipengaruhi oleh variabel pendapatan.

\section{ANALISIS TANGGAPAN TERHADAP VARIABEL LATEN KEPUASAN KONSUMEN (KP)}

Variabel Kepuasan Konsumen ditentukan dengan 3 indikator yaitu service (Y1), expectasion (Y2), dan price quality ratio (Y3), ketiga indikator ini merpakan variabel manifest yang menjelaskan variabel laten kepuasan dan terbagi menjadi 4 item pertanyaan. hasil wawancara dapat dilihat sebagai berikut:

Tabel 17. Persentase Tanggapan Konsumen Terhadap Kepusan Konsumsen

\begin{tabular}{|c|c|c|c|c|c|c|}
\hline \multirow[b]{2}{*}{ No } & \multirow[b]{2}{*}{ Indikator Varibel Kepuasan Konsumen } & \multicolumn{5}{|c|}{ Banyak Konsumen } \\
\hline & & $\begin{array}{c}\text { Sangat } \\
\text { Tidak } \\
\text { Setuju }\end{array}$ & $\begin{array}{l}\text { Tidak } \\
\text { Setuju }\end{array}$ & $\begin{array}{l}\text { Kurang } \\
\text { Setuju }\end{array}$ & Setuju & $\begin{array}{l}\text { Sangat } \\
\text { Setuju }\end{array}$ \\
\hline 1 & $\begin{array}{l}\text { Anda puas dengan pelayanan yang } \\
\text { diberikan oleh XYZ Kota Bengkulu. }\end{array}$ & $0 \%$ & $0 \%$ & $13 \%$ & $77 \%$ & $10 \%$ \\
\hline 2 & XYZ telah memenuhi harapan anda & $0 \%$ & $1 \%$ & $18 \%$ & $74 \%$ & $8 \%$ \\
\hline 3 & Anda merasa senang makan di $X Y Z$ & $0 \%$ & $1 \%$ & $7 \%$ & $78 \%$ & $14 \%$ \\
\hline 4 & $\begin{array}{l}\text { Anda puas dengan harga yang ditetapkan } \\
\text { XYZ dan sudah sesuai dengan kualitas } \\
\text { yang diberikan. }\end{array}$ & $0 \%$ & $1 \%$ & $15 \%$ & $74 \%$ & $11 \%$ \\
\hline & $\begin{array}{l}r \text { : data primer diolah, } 2017 \\
\text { Dari variabel diatas yang menjadi in }\end{array}$ & kator & servi & adalah & indika & or no. \\
\hline
\end{tabular}


JURNAL ILMIAH SOSIO-EKONOMIKA BISNIS

eISSN: 1412-8241 (p); 2621-1246 (e), Volume 21. no (1) 2018

DOI: https://doi.org/10.22437/jiseb.v21i1.5101

dibuktikan dengan lebih dari $70 \%$ konsumen telah menyatakan setuju dan rata-rata $10 \%$ menjawab sangat setuju.

\section{ANALISIS TANGGAPAN TERHADAP VARIABEL LATEN LOYALITAS KONSUMEN}

Indikator loyalitas atau variabel manifest loyalitas konsumen terbagi manjadi 3 indikator yaitu melkaukan pembelian secara berulang (Y4), merekomendasikan kepada orang lain (Y5) dan kebal terhadap pesaing (Y6), hasil jawaban konsumen disajikan dalam tabel berikut:

Tabel 18. Persentase Tanggapan Konsumen Terhadap Loyalitas Konsumsen

\begin{tabular}{ccccccc}
\hline \multirow{2}{*}{$\mathrm{N}$} & Indikator Varibel Loyalitas Konsumsen & $\begin{array}{c}\text { Sangat } \\
\text { Tidak } \\
\text { Setuju }\end{array}$ & $\begin{array}{c}\text { Tidak } \\
\text { Setuju }\end{array}$ & $\begin{array}{c}\text { Kurang } \\
\text { Setuju }\end{array}$ & Setuju & $\begin{array}{c}\text { Sangat } \\
\text { Setuju }\end{array}$ \\
\hline 1 & $\begin{array}{l}\text { Anda selalu melakukan pembelian secara } \\
\text { berulang pada produk XYZ ini. }\end{array}$ & $0 \%$ & $2 \%$ & $14 \%$ & $69 \%$ & $16 \%$ \\
2 & $\begin{array}{l}\text { Anda telah merekomendasikan kepada } \\
\text { orang lain untuk makan di XYZ. }\end{array}$ & $1 \%$ & $4 \%$ & $17 \%$ & $66 \%$ & $13 \%$ \\
3 & $\begin{array}{l}\text { Anda jarang melakukan peralihan ke } \\
\text { makanan cepat saji lainnya. }\end{array}$ & $1 \%$ & $5 \%$ & $25 \%$ & $63 \%$ & $6 \%$ \\
4 & $\begin{array}{l}\text { XYZ merupakan pilihan pertama jika } \\
\text { ingin makan di restoran cepat saji }\end{array}$ & $1 \%$ & $6 \%$ & $25 \%$ & $57 \%$ & $12 \%$ \\
5 & $\begin{array}{l}\text { Percaya bahwa XYZ merupakan restoran } \\
\text { cepat saji terbaik. }\end{array}$ & $0 \%$ & $2 \%$ & $21 \%$ & $68 \%$ & $10 \%$ \\
\hline
\end{tabular}

Sumber : data primer diolah, 2017

Dari variabel diatas yang menjadi indikator item pertanyaan untuk no.3, no.4 dan no.5 merupakan indikator pertanyaan untuk variabel kebal terhadap pesaing. Dari tabel diatas rata-rata konsumen menjawab setuju sehingga disimpulkan rata-rata konsumen berdasarkan indikator yang menyusunnya telah loayalitas. Hal ini dibuktikan dengan lebih dari $60 \%$ konsumen telah menyatakan setuju dan rata-rata $10 \%$ menjawab sangat setuju kecuali yitem no. 3 hanya $6 \%$ menjawab sangat setuju.

\section{ANALISIS STRUCTURAL EQUATION MODELING}

\section{Kesesuaian Model Dengan Penelitian}

Sebelum dilakukan analisis kecocokan keseluruhan model, dapat dijelaskan bahwa dari hasil uji Confirmatory Factor Analysis (CFA) dari 15 indikator, terdapat 2 indikator yang dihilangkan dari variabel laten yang membentuknya, antara lain X4 dan X5.

Tabel 19. Hasil uji Confirmatory Factor Analysis (CFA) dari indikator yang membentuk suatu variabel laten

\begin{tabular}{|c|c|c|c|c|c|c|c|c|}
\hline \multirow[t]{2}{*}{$\overline{\mathrm{No}}$} & \multirow{2}{*}{$\begin{array}{c}\text { Kode } \\
\text { Indikator }\end{array}$} & \multirow{2}{*}{$\begin{array}{l}\text { Standardized } \\
\text { Loading Factor } \\
\text { (SLF) } \geq 0.5\end{array}$} & \multirow{2}{*}{$\begin{array}{c}\text { Standard } \\
\text { error }\end{array}$} & \multirow{2}{*}{$\begin{array}{c}\mathrm{t}- \\
\text { values }\end{array}$} & \multirow{2}{*}{$\begin{array}{c}\text { Error } \\
\text { variance }\end{array}$} & \multirow[t]{2}{*}{ Keterangan } & \multicolumn{2}{|c|}{ realiblitas } \\
\hline & & & & & & & $\begin{array}{l}\mathrm{CR} \geq \\
0.70\end{array}$ & $\begin{array}{l}\mathrm{VE} \geq \\
0.50\end{array}$ \\
\hline 1 & 2 & 3 & 4 & 5 & 6 & 7 & 8 & 9 \\
\hline 1. & $\mathrm{X} 1$ & 0.82 & 0.33 & 9.44 & 0.043 & Valid & 0.82 & 0.75 \\
\hline 2. & $\mathrm{X} 2$ & 0.70 & 0.51 & 7.63 & 0.110 & Valid & & \\
\hline 3. & X3 & 0.60 & 0.64 & 6.23 & 0.240 & Valid & & \\
\hline
\end{tabular}


JURNAL ILMIAH SOSIO-EKONOMIKA BISNIS

eISSN: 1412-8241 (p); 2621-1246 (e), Volume 21. no (1) 2018

DOI: https://doi.org/10.22437/jiseb.v21i1.5101

\begin{tabular}{|c|c|c|c|c|c|c|c|c|}
\hline No & $\begin{array}{c}\text { Kode } \\
\text { Indikator }\end{array}$ & $\begin{array}{l}\text { Standardized } \\
\text { Loading Factor } \\
(\mathrm{SLF}) \geq 0.5\end{array}$ & $\begin{array}{l}\text { Standard } \\
\text { error }\end{array}$ & $\begin{array}{c}\mathrm{t}- \\
\text { values }\end{array}$ & $\begin{array}{c}\text { Error } \\
\text { variance }\end{array}$ & Keterangan & $\begin{array}{l}\text { realil } \\
C R \geq \\
0.70\end{array}$ & $\begin{array}{l}\text { blitas } \\
\text { VE } \geq \\
0.50\end{array}$ \\
\hline 1 & 2 & 3 & 4 & 5 & 6 & 7 & 8 & 9 \\
\hline 4. & $\mathrm{X} 4$ & 0.47 & 0.78 & 4.71 & 0.140 & $\begin{array}{l}\text { Tidak } \\
\text { Valid }\end{array}$ & & \\
\hline 5. & X5 & 0.47 & 0.78 & 4.67 & 0.140 & $\begin{array}{l}\text { Tidak } \\
\text { Valid }\end{array}$ & & \\
\hline 6. & $\mathrm{X} 6$ & 0.69 & 0.52 & 7.46 & 0.098 & Valid & & \\
\hline 7. & $\mathrm{X} 7$ & 0.61 & 0.62 & 6.42 & 0.190 & Valid & & \\
\hline 8. & $\mathrm{X} 8$ & 0.73 & 0.47 & 2.30 & 0.31 & Valid & 0.80 & 0.77 \\
\hline 9. & $\times 9$ & 0.94 & 0.12 & 2.34 & 0.11 & Valid & & \\
\hline 10. & Y1 & 0.81 & 0.32 & 9.22 & 0.073 & Valid & 0.88 & 0.85 \\
\hline 11. & $\mathrm{Y} 2$ & 0.86 & 0.26 & 9.73 & 0.056 & Valid & & \\
\hline 12. & $\mathrm{Y} 3$ & 0.61 & 0.62 & 6.37 & 0.18 & Valid & & \\
\hline 13. & $\mathrm{Y4}$ & 0.57 & 0.68 & 5.56 & 0.26 & Valid & 0.72 & 0.62 \\
\hline 14. & Y5 & 0.57 & 0.67 & 5.65 & 0.35 & Valid & & \\
\hline 15. & Y6 & 0.74 & 0.45 & 7.61 & 0.13 & Valid & & \\
\hline
\end{tabular}

Sumber: Output Liarel olahan peneliti, 2017

Tabel diatas menunjukkan bahwa seluruh variabel termati atas variabel laten DG (Demographic), KP (Kepuasan Konsumen) dan LY (Loyalitas Konsumen) telah lolos uji validitas, karena semua variabel manives telah memenuhi syarat yaitu memiliki nilai loading factors $\geq 0.50$ dan nilai $t$-value $\geq 1$.98. Kriteria $t$-value diperoleh dari perhitungan menggunakan t-tabel dengan menggunakan tingkat kepercayaan 95\%. Namun tidak dengan variabel laten EX (Extended Marketing Mix) dimana variabel manifes X4 dan X5 tidak memenuhi syarat dengan nilai loading factors $<0.50$, sehingga harus dihapuskan dari variabel EX..

Sedangkan uji reliabilitas variabel, untuk keseluruhan variabel menghasikan nilai yang sangat baik, dimana semua nilai memenuhi kriteria yang ada.Dapat dilihat pada tabel diatas, bahwa construct reliability (CR) memiliki nilai $\geq 0.70$ yang merupakan kriteria dari terpenuhinya construct reliability (CR) yang baik dan variance extracted (VE) dengan kriteria VE $\geq 0.50$. dari tabel diatas dapat dikatakan bahwa variabel EX (Extended Marketing Mix), DG (Demographic), KP (Kepuasan Konsumen) dan LY (Loyalitas Konsumen) memiliki konsistensi yang baik.

Uji kecocokan keseluruhan model dilakukan setelah dilaksanakannya modifikasi model hybrid yang dihasilkan, sampai model dikatakan fit. Jika model masih belu dikatakan fit maka dilakukan modifikasi model yang disarankan oleh hasil output LISREL (modification indices). Analisa kecocokan keseluruhan model dapat dilihat dari angka statistic sebagai berikut, yaitu: 
Tabel 20. Hasil Uji Kecocokan Keseluruhan Model

\begin{tabular}{|c|c|c|c|c|}
\hline No & $\begin{array}{c}\text { Ukuran } \\
\text { Goodness Of } \\
\text { Fit (GOF) }\end{array}$ & $\begin{array}{l}\text { Target Tingkat } \\
\text { Kecocokan }\end{array}$ & $\begin{array}{c}\text { Estimasi } \\
\text { Respesifikasi }\end{array}$ & $\begin{array}{c}\text { Tingkat } \\
\text { Kecocokan }\end{array}$ \\
\hline 1. & $\begin{array}{l}\text { Chi-Square } \\
\mathrm{P}\end{array}$ & Nilai yang kecil & $X^{2}=86.69$ & Marginal Fit \\
\hline 2. & $\mathrm{X}^{2} / \mathrm{df}$ & $\mathrm{X}^{2} / \mathrm{df}<5$ atau $\mathrm{X}^{2} / \mathrm{df}<2$ & $\mathrm{X}^{2} / \mathrm{df}=1,55$ & Good fit \\
\hline 3. & $\begin{array}{l}\mathrm{NCP} \\
\text { Interval }\end{array}$ & $\begin{array}{l}\text { Nilai yang kecil } \\
\text { Interval yang sempit }\end{array}$ & $\begin{array}{l}27.69 \\
(0.067 ; 0.56)\end{array}$ & Marginal fit \\
\hline 4. & RMSEA & $0.05 \leq$ RMSEA $\leq 0.08$ & RMSEA $=0.063$ & Good fit \\
\hline 5. & EVCI & $\begin{array}{l}\mathrm{EVCI} \leq \mathrm{EVCI} \text { saturated } \\
\mathrm{EVCI} \leq \mathrm{EVCI} \text { independece }\end{array}$ & $\begin{array}{l}\text { EVCI = } 1.49 \\
\text { EVCI saturated = } 1.80 \\
\text { EVCI independece = } \\
9.17\end{array}$ & Good fit \\
\hline 6. & AIC & $\begin{array}{l}\mathrm{AIC} \leq \mathrm{AIC} \text { saturated } \\
\mathrm{AIC} \leq \mathrm{AIC} \text { independece }\end{array}$ & $\begin{array}{l}\text { AIC }=150.69 \\
\text { AIC saturated }=182 \\
\text { AIC independece }= \\
926.03\end{array}$ & Good fit \\
\hline 7. & CAIC & $\begin{array}{l}\text { CAIC } \leq \text { CAIC saturated } \\
\text { CAIC } \leq \text { CAIC independece }\end{array}$ & $\begin{array}{l}\text { CAIC }=266.69 \\
\text { CAIC saturated }= \\
511.87 \\
\text { CAIC independece }= \\
973.15\end{array}$ & Good Fit \\
\hline 8. & NFI & NFI $\geq 0.90$ & $\mathrm{NFI}=0.90$ & Good Fit \\
\hline 9. & NNFI & $\mathrm{NNFI} \geq 0.90$ & $\mathrm{NNFI}=0.95$ & Good Fit \\
\hline 10. & CFI & $\mathrm{CFI} \geq 0.90$ & $\mathrm{CFI}=0.96$ & Good Fit \\
\hline 11. & IFI & IFI $\geq 0.90$ & $\mathrm{IFI}=0.96$ & Good Fit \\
\hline 12. & RFI & $\begin{array}{l}\mathrm{RFI} \geq 0.90 \\
0.90 \leq \mathrm{RFI} \leq 0.90\end{array}$ & $\mathrm{RFI}=0.87$ & Marginal Fit \\
\hline 13. & RMR & $\begin{array}{l}\text { Standardized RMR } \\
\leq 0.05\end{array}$ & $\mathrm{RMR}=0.025$ & Good Fit \\
\hline 14. & GFI & GF1 $\geq 0.90$ & GFI $=0.88$ & Marginal Fit \\
\hline 15. & AGFI & $\mathrm{AGFI} \geq 0.90$ & $\mathrm{AGFI}=0.82$ & Marginal Fit \\
\hline 16. & PGFI & PGFI > AGFI & PGFI $=0.57$ & Kurang baik \\
\hline
\end{tabular}

Sumber: Output Lisrel hasil olahan peneliti, 2017

Dari hasil uji kecocokan keseluruhan model tersebut diatas, 2 ukuran goodness of fit (GOF) 1 ukuran goodness of fit (GOF) yang menunjukkan kecocokan yang kurang baik, 5 ukuran GOF yang menunjukkan kecocokan cukup baik (marjinal fit) dan 10 ukuran GOF yang menunjukkan kecocokan yang baik (Good fit). Sehingga dapat disimpulkan bahwa kecocokan keseluruhan model adalah baik 


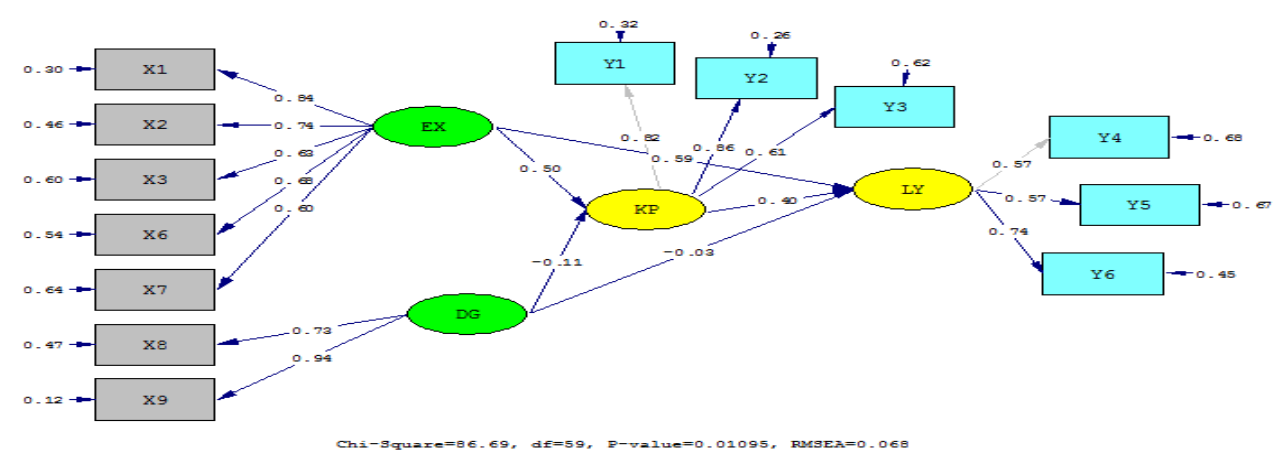

Gambar 1.a. Path diagram Standard solutions model hybrid

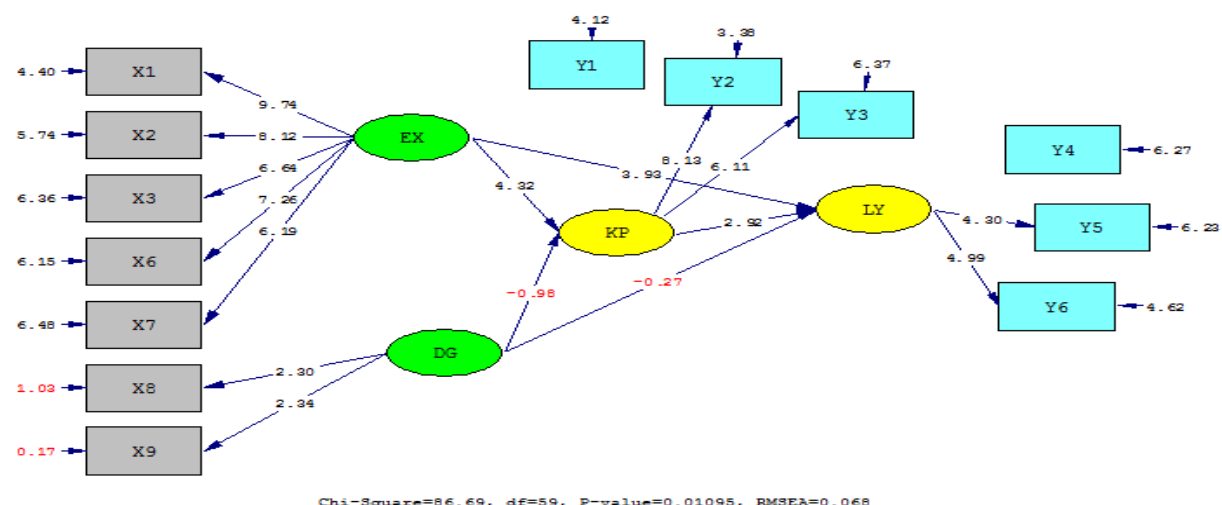

Gambar 1.b. Path diagram T-Value model hybrid

\section{Pengujian Hipotesis}

Berdasarkan hasil uji hipotesis, terdapat tiga dari lima hipotesis penelitian membuktikan adanya hubungan signifikan pada tingkat keyakinan $95 \%$ dengan $t$-value $\geq$ 1.98. Secara umum hasil tabel 16 menandakan hubungan variabel independen terhadap variabel dependen terkait pada gambar 1.a dan 1.b sebagai hasil pengukuran struktural second order CFA (2ndCFA).

Tabel 21. Kesimpulan Uji Hipotesis

\begin{tabular}{clccc}
\hline Hipotesis & \multicolumn{1}{c}{ Path } & T-Value & Estimasi & Hasil \\
\hline H1 & $\begin{array}{l}\text { EX (Extended Marketing Mix) } \rightarrow \text { KP } \\
\text { (Kepuasan Konsumen) }\end{array}$ & 4.32 & 0.5 & Diterima \\
H2 & $\begin{array}{l}\text { DG (Demografy) } \rightarrow \text { KP (Kepuasan } \\
\text { Konsumen) }\end{array}$ & -0.98 & -0.11 & Ditolak \\
H3 & $\begin{array}{l}\text { EX (Extended Marketing Mix) } \rightarrow \text { LY } \\
\text { (Loyalitas Konsumen) }\end{array}$ & 3.93 & 0.59 & Diterima \\
H4 & $\begin{array}{l}\text { DG (Demografy) } \rightarrow \text { LY (Loyalitas } \\
\text { Konsumen) }\end{array}$ & -0.27 & -0.03 & Ditolak \\
H5 & $\begin{array}{l}\text { KP (Kepuasan Konsumen) } \rightarrow \text { LY } \\
\text { (Loyalitas Konsumen }\end{array}$ & 2.92 & 0.40 & Diterima \\
\hline
\end{tabular}

Sumber: Output Lisrel Hasil Olahan Peneliti, 2017

\section{KESIMPULAN}

\section{PENUTUP}

Dari hasil yang dilakukan maka dapat disimpulkan bahwa dari variabel extended marketing mix terdapat 2 variabel manifest menyusunnya yang dianggap tidak memiliki akurasi terhadap extended marketing mix yaitu variabel promotion dan people sehingga 
JURNAL ILMIAH SOSIO-EKONOMIKA BISNIS

eISSN: 1412-8241 (p); 2621-1246 (e), Volume 21. no (1) 2018

DOI: https://doi.org/10.22437/jiseb.v21i1.5101

kedua variabel ini tidak berpengaruh signifikan. Variabel extended marketing mix yang dianggap mempunyai pengaruh adalah variabel product, price, place, physical evidence dan process secara langsung memiliki pengaruh signifikan terhadap kepuasan dan loyalitas konsumen. Secara tidak langsung variabel extended marketing mix mempengaruhi kepuasan konsumen dan kepuasan konsumen mempengaruhi loyalitas. Sedangkan faktor demografi tidak mempunyai pengaruh signifikan terhadap kepuasan konsumen maupun loyalitas secara langsung. Faktor demografi tidak mempunyai pengaruh signifikan terhadap loyalitas hubungan secara langsung ataupun secara tidak langsung melalui variabel kepuasan konsumen.

\section{SARAN}

Dari hasil uji yang dilakukan, hendaknya pihak produsen memperhatikan bauran pemasaran yang ada, dimana varibel product, price, place,physical evidence dan process paling berpengaruh terhadap kepuasan dan loyalitas. Salah satu dari konsumen mengeluhkan menu XYZ yang tidak tersedia atau habis, serta pelayanan yang masih dianggap kurang baik. Sedangkan variabel promotion dan people tidak terlalu memiliki akurasi yang tinggi dikarenakan konsumen yang menkonsumsi cukup banyak mengetahui informasi dari teman dan keluarga.

\section{DAFTAR PUSTAKA}

Hurriyati, Ratih. 2010. Bauran Pemasaran \& Loyalitas Konsumen (fokus pada konsumen kartu redit dan perbankan). Cetakan Ketiga. Penerbit CV Alfabeta. Bandung.

Nasution, Ahmadriswan. 2015. SEM: Structural Equation Modelling. Pusdiklat BPS, ahmadriswan@bps.go.id

Patimah, Stiti. 2016. Analisis Tingkat Kepuasan Konsumen Terhadap Usaha Benih Padi Cigeulis di Balai Benih Induk Padi dan Palawija (BBIP) di Kabupaten Kepahiang Provinsi Bengkulu. Skripsi. Program Stdi Agrbisnis. Fakultas Pertanian. UNIB. Bengkulu.

Pradika, Wanda. 2013. Pengaruh Service Convinience terhadap keputuasan pembelian (Survey pada konsumen McDonald's King Dept. Store). Skripsi. Program Studi Manajemen.Fakulats Pendidikan Ekonomi dan Bisnis. Universitas Pendidikan Indonesia. http://repository.upi.edu/6139/ (diakses 10 Februari 2017 Pukul $08.50 \mathrm{Wib})$.

Rosana, E. 2011. Moderenisasi dan Perubahan Sosial. Jurnal Ilmiah. ejournal.radenintan.ac.id (diakses pada 25 Januari 2017pukul 19.17 WIB).

Sarjono, H dan Winda J. 2014. Structural Equation Modelling (SEM), Sebuah Pengantar Aplikasi Untuk Penelitian Bisnis. Salemba Empat. Jakarta. 